\title{
Lateral groundwater flow and pond interactions during dry and wet years
}

\section{Andrew Wicke, Thair Patros, Gary Parkin}

School of Environmental Sciences, Ontario Agricultural College, University of Guelph, Guel ph, ON Canada. Faculty Supervis or: Dr. Gary Parkin. For correspondence, please email: gparkin@uoguelph.ca.

\section{Abstract}

Groundwater and surface water are tightly coupled elements of the hydrologic cycle that have often been treated as separate entities. Future climate change modelling has predicted that hydrologic cycle changes, namely increasing drought frequency and flood-type events, are likely to occur. These events may directly impact the quality and quantity of both groundwater and surface water. Future water management policies must therefore be based on an understanding of how interactions between groundwater and surface water will change with a warming climate. The aim of this study was to model and analyze the lateral flow of groundwater and its interactions with a nearby pond in a shallow, unconsolidated, unconfined aquifer. Data were collected as part of a larger and ongoing study during the year 2012, a comparatively dry year, and 2013, a comparatively wet year. We first used ArcGIS and Visual MODFLOW Flex to create a conceptual model of the system, its soil layers, monitoring wells, and potential flow patterns. We then analyzed hydraulic head data, and calculated groundwater flow volumes using the Dupuit equation. We found that the groundwater flow direction reversed in the summer of 2012 and continued until the spring of 2013. Additonally, flow rate was greater in 2013 than 2012 . The flow reversal was likely caused by higher evaporative demand during the summer months of 2012, drawing substantially more water from the pond than from the soil. The two-year timeframe was not long enough to determine whether this was a typical, yearly pattern, or was primarily due to the fact that $\mathbf{2 0 1 2}$ was a particularly dry year.

Keywords: Groundwater; Surface water; Pond interactions; Lateral groundwater flow; Unconfined aquifer.

\section{Introduction}

Groundwater and surface water are two interconnected components of the hydrologic cycle. Any physical or chemical change that takes place in one will, in turn, affect the other. Changes to groundwater recharge or discharge that occur through variable weather patterns may have a significant impact on groundwater flow regimes, particularly within small, local-scale systems (Sophocleous 2002). Climate change models predict that extreme events such as droughts and floods will become more frequent in the future (Taylor et al. 2013). It is still uncertain how these extreme events will affect the already complex nature of groundwater-surface water interactions. The best strategy for guiding future water management policy is therefore to better understand how climatic fluctuations affect the local-scale interactions that occur between these two important hydrologic components. Efforts to better quantify these processes have led to the development of sophisicated computer modelling and GIS applications. These allow complex aquifer systems to be abstracted, and flow calculations to be computed accurately, provided the data are of high quality. This study aimed to conceptualize and to quantify the lateral flow of groundwater at a shallow aquiferpond interface during the years 2012 and 2013. The year 2012 was a relatively dry, while 2013 was comparatively wet. Modelling was utilized not only to allow ease of 3-D visualization of the system and of changes in water flow patterns, but also to explore the potential for future modelling of small groundwater and surface water systems. Lab and field data were used to create a 3-D conceptual model of the groundwater system, and an analytical solution was applied to calculate subsurface saturated flow over the two years studied. Analysis of groundwater flow patterns may indicate some of the changes that may occur as a result of future climatic change and changes to rainfall inputs.

\section{Objectives}

This study had three main objectives. The first was to review the literature concerning lateral groundwater flow and its interactions with surface waters, and the potential for groundwater modelling of these types of systems. The second was to create a conceptual model of the research area as a preliminary system model, using groundwater modelling and GIS software, namely Visual MODFLOW Flex, v2014, and ArcMap v10.2. The purpose of the model was to visualize the shallow aquifer system in $3-\mathrm{D}$, as well as to explore the future potential of groundwater modelling of small, surface water-dominated local systems. The third objective was to apply the numerical capabilities of the modelling software and groundwater flow equations to 
characterize the lateral groundwater flow during 2012 and 2013. To do so, we used pre-existing hydrogeological data gathered from the Arboretum, located at the University of Guelph, in Guelph, Ontario.

\section{Literature review}

\section{Theory of groundwater flow}

Water exists below the earth's surface in void spaces, cracks in rocks, and between soil particles. Where the geologic material transitions from unsaturated to completely saturated conditions marks the position of the water table (Fetter 2001). The flow of groundwater below the water table, within the saturated zone, is well understood. Within an unconfined aquifer system, the shape of the water table roughly follows the land surface above. Higher elevations are typically matched by a higher water table, which follows a similar regional slope as the land surface (National Research Council [NRC] 1990; Fetter 2001). Hydrostatic pressure in this region is proportional to the potential energy contained within the height of the water, measured in respect to a specific datum (NRC 1990; Fetter; 2001). The most commonly used datum is the mean sea level, and elevations are given in meters above sea level (m ASL).

Rainwater that lands on the soil surface may infiltrate the unsaturated or vadose zone (NRC 1990; Zomorodi 1991; Fetter 2001). If the water does not evaporate or adhere to soil particles, and is not intercepted by plant roots, it will continue its movement downward. Continued water movement past the root zone is referred to as deep drainage (Touhami et al. 2013). When the water reaches the top of the water table, it becomes groundwater recharge (NRC 1990; Zomorodi 1991). Locally, the infiltration of water into the soil depends upon the amount of precipitation on the surface, the topography, the antecedent moisture conditions, soil hydraulic properties, and the degree of soil compaction (Zomorodi 1991; Touhami et al. 2013). Flow through the unsaturated zone will be less than through the saturated zone, as unsaturated sediments induce a negative suction pressure on water, with the force exerted determined by the amount of water currently held in the soil (Fetter 2001).

The total energy in the saturated zone is proportional to the pressure from the height of the column of water and its elevation with respect to the given datum. The sum of these two components is the hydraulic head, $h$. When the difference in hydraulic head between two separate points is divided by the distance between them, it yields the hydraulic gradient, $d h / d l$ (where $l$ is the distance between the two measured $h$ values). Where there is a nonzero gradient, water will flow from a high hydraulic head to low hydraulic head. The ease with which groundwater flows through a porous medium is determined by the pore size distribution of and pore connectivity of the material. This is a parameter known as hydraulic conductivity, $K$ (unit length, [L]/time, [t]).
The simplified Darcy's Equation [1] represents this relationship:

$$
q=-K \frac{d h}{d l}
$$

where $q[\mathrm{~L}] /[\mathrm{t}]$ is the Darcian "velocity" of the flow (it is not a true velocity in this case, as the fluid is moving through a porous medium and therefore must take a longer path than if it were simply following a straight path, in equal time). This is the principal groundwater flow equation and is the basis of most analytical solutions and numerical models developed in hydrogeology (NRC 1990; Fetter 2001).

\section{Groundwater flow systems}

Any geologic unit that contains and transmits water can be considered an aquifer. Aquifers range in complexity and are controlled by the physical and chemical makeup of the rock and sediments of which they are composed. The nature of groundwater flow across and between aquifers differs depending on scale. At the largest scale are regional groundwater flow systems. These often comprise deeper reserves of groundwater, which flow over great distances from a regional water table high to the major water table low. These systems are typically considered over entire watersheds (Winter 1998; Sophocleous 2002). Regional flow systems consist of numerous intermediate regimes (which may connect various bodies of water), and, within these, local regimes. Local flow regimes occur on much smaller scales, such as between a stream and its banks (Winter 1998; Fetter 2001; Sophocleous 2002).

The flow of groundwater per unit width in an unconfined aquifer can be calculated between two points of hydraulic head $h$, separated by a distance 1 , using the Dupuit equation [2]:

$$
q^{\prime}=-\frac{1}{2} K\left(\frac{h_{1}^{2}-h_{2}^{2}}{L}\right)
$$

where $q^{\prime}$ is the flow per unit width $\left[\mathrm{L}^{3}\right] /([\mathrm{L}][\mathrm{t}], K$ remains the hydraulic conductivity, $h_{1}$ is the head at the origin [L], and $h_{2}$ is head at another point at distance l [L]. This solution assumes, however, that the aquifer is homogenous and isotropic ( $K$ is the same in all directions), that the hydraulic gradient is equal to the slope of the water table, and that there is no vertical movement of water (Fetter 2001). This solution allows for a volumetric flow, denoted $Q\left[\mathrm{~L}^{3} / \mathrm{t}\right]$ to be calculated if the width of the aquifer is known.

The network of flow systems for a given area is governed by the distribution of permeable and impermeable layers, in conjunction with depressions, topographic highs, and breaks in slope. Recharge from deep drainage feeds the system as water seeps out into streams, lakes, springs, or other areas (NRC 1990; Zomorodi 1991; Sophocleous 2002). When recharge volume is matched by discharge volume, the amount of water stored in the aquifer remains constant. Changes to either inputs or outputs will affect the amount of water stored and the height of the water table. When water leaving exceeds inflow (such as during extensive water pumping or high evaporation rates), the amount of stored 
water is diminished, and the water table drops (NRC 1990; Fetter 2001). Conversely, where inflow exceeds outflow, the water table rises (NRC 1990; Fetter 2001).

Flow systems are highly variable and change frequently with fluctuations in rainfall and recharge rates. Regional systems tend to respond more slowly to changes due to their greater breadths, while local and intermediate regimes react relatively rapidly to fluctuations (NRC 1990; Winter 1998; Fetter 2001; Sophocleous 2002; Gregor 2012).

Direct rainfall and runoff cause an immediate rise in surface water level, while groundwater responds more slowly, as water must first travel through the soil profile (Winter 1998; Fetter 2001; Sophocleous 2002). Additionally, water evaporates more readily from surface water bodies than through soil or rock. As a result, head differences between groundwater and surface water fluctuate. The quicker response time in surface water can raise or lower water levels in the soil (in relation to the water table), thereby changing the hydraulic gradient. If the gradient shifts too far in one direction, groundwater discharge may stagnate or reverse direction completely (Gregor 2012; Rodhe and Seibert 2011). Carlson and Lyford (2005) observed this in wetlands, which acted as recharge areas in the spring and early summer, and as discharge areas during the late summer and fall. Fraser et al. (2001) found that within peat bogs, rainfall and evapotranspiration differences directly affected flow directions. The bogs consisted of highly porous peat that remained mostly saturated throughout the year, but underwent seasonal changes in hydraulic head. During periods in which rainfall was heavier, such as in early spring and late fall, water levels in the bog were higher than in the nearby water table, and the bog acted as a recharge zone. Conversely, during the dry summer months when evaporation was higher than rainfall, more water evaporated from the open bog than from the neighbouring soils. As such, the gradient then changed, discharging toward the bog. Fraser et al. (2001) noted that during these periods, changes in flow direction were caused by the quicker response of the peat to changes in rainfall and evaporation. The peat responded more quickly than the geologic material in the aquifer, due to its higher hydraulic conductivity (Fraser et al. 2001). Changes in head differentials between points also affect the velocity and volume of water moving laterally through the aquifer (NRC; 1990).

Hydraulic conductivity varies spatially in all real aquifers, as geological materials are never homogeneous or isotropic outside of a laboratory setting (Fetter 2001; Sophocleous 2002). The assumption that such systems are isotropic is often made in order to simplify the governing equations used in calculating flow (Fetter 2001).

\section{Computer modelling and geographic information systems (GIS)}

Much of the difficulty in visualizing and estimating 3-D groundwater flow in complex systems can be addressed by using computer modelling. Groundwater computer models allow for the 3-D visualization and computation of water movement within the saturated zone. This modelling is based on specified geological and hydrological conditions, after which most models solve numerical equations to estimate the groundwater flow. The integration of mathematical models with ever-increasing computational power has helped to create powerful software capable of modelling intricate systems.

One series that has become an industrial and academic standard is the MODFLOW platform. Originally developed by the United States Geological Survey (USGS), this open source software has been (and continues to be) modified and improved through different iterations and add-on packages. These packages allow for different aquifer and environmental interactions to be modelled (Wang et al. 2008; Brunner et al. 2010).

Models often allow for both conceptual and numerical modelling. Conceptual modelling typically represents the surface topography and subsurface stratigraphy as 3-D layers. Conceptual models also allow for the characterization of features such as the surface water bodies, locations and depths of wells, and the boundaries of the study site. Numerical modelling uses the constructed conceptual model and a 3-D grid or mesh to calculate the flow of groundwater. It does so primarily by using the principal 3-D groundwater flow equation [3] to determine the flow volume and direction for each grid cell. This equation describes the mass-balance relationship between water moving into and out of each grid cell, based on initial hydraulic heads and conductivity (Wang et al. 2008; Rajamanickam and Nagan 2010):

$\left(\frac{\partial}{\partial x} K_{x} \frac{\partial h}{\partial x}\right)+\left(\frac{\partial}{\partial y} K_{y} \frac{\partial h}{\partial y}\right)+\left(\frac{\partial}{\partial z} K_{z} \frac{\partial h}{\partial z}\right)+W=S_{s} \frac{\partial h}{\partial t}$

where the $K$ values for dimensions $x, y$, and $z$ are considered, along with hydraulic head, $h$, volumetric flow per unit volume $W\left[\mathrm{~L}^{3}\right] /\left[\mathrm{L}^{3}\right][\mathrm{t}]$, specific storage $S_{s}\left[\mathrm{~L}^{-1}\right]$ and time, [t] (NRC 1990; Fetter 2001; Wang et al. 2008; Rajamanickam and Nagan 2010).

Models are occasionally used in conjunction with geographic information systems (GIS). GIS are software developed to display and analyze geospatial data. The wide array of statistical and processing tools within GIS technology allows for the solving of various geospatial problems, and can be used to convert and link together other spatial and non-spatial data forms (Wang et al. 2008; Rajamanickam and Nagan 2010). In modelling applications, GIS can be used to create input files with attached spatial attributes such as geographic coordinates and elevations, as well as attribute data such as hydraulic conductivity and soil type. GIS platforms also allow for data visualization and the creation of detailed maps. For groundwater modelling, they allow for easy pre-processing of raw data, defining the areal extent and topographic surfaces of the layers, and the position of wells, infrastructure, or boundary conditions, in 3-D space. Within the ArcGIS platform (developed by ESRI), ArcMap is a commonly used GIS tool, popular in 
variety of industries for its versatility and ease of use (Wang et al. 2008; Rajamanickam and Nagan 2010).

\section{Materials and methods}

\section{Studyarea}

The $1500 \mathrm{~m}^{2}$ study site lies within Victoria Woods in the University of Guelph's Arboretum. The area consists of a series of woods, wetlands, walking trails and gardens, and is currently used as a "living laboratory" by researchers at the University of Guelph. The study site, seen in Figure 1, slopes gently and is located next to a restored gravel pit which is now submerged in water. The surrounding woods are predominately maple, with shallow root depths due to seasonal flooding (Arboretum Master Plan Steering Committee 2004). Excavation of the former gravel pit led to the piling of topsoil, which now comprises much of the material at the site (Tamang et al., unpublished study, 2014).

The primary hydrogeological units are comprised of unconsolidated glacial overburden on top of fractured dolomite bedrock. The Guelph landscape was sculpted by glaciation events during the Pleistocene, with the Wisconsin Glaciation (approximately 11,000 years prior) being the most recent. These events marked the area with complex deposits of glacial till, left as drumlins and moraines and sorted sandy outwash plains (Karrow 1968; Gartner Lee Ltd. 2004; Bajc et al. 2014). The City of Guelph is situated within the aptly named Guelph Drumlin Field, and much of the city is built on or around large drumlin features. A large drumlin lies just southwest of the study site (Best 2013).

Overburden thickness at the Arboretum site is approximately $10 \mathrm{~m}$. Underlying the glacial drift are the Silurian-age Guelph and Amabel Formations. These formations consist primarily of massively bedded dolomite with thin shale interbeds. The bedrock formation was the result of extensive reef complexes which flourished in the epicontinental sea that once covered the Michigan Basin during much of the Paleozoic (Gartner Lee Ltd. 2004; Bajc et al. 2014).

A consulting report by Gartner Lee Ltd. (2004) noted that the fractured bedrock units are partly confined in some areas by the glacial overburden, which has highly variable hydraulic conductivities. Because of this, the City of Guelph draws drinking water mainly from these deeper dolomite aquifer units. The water that exists in the shallow, unconsolidated aquifers above remains hydraulically connected to the bedrock aquifer in many places, but is not substantially drawn on for water (Gartner Lee Ltd. 2004).

\section{Data}

Modelling the Arboretum system involved the use of pre-existing hydrogeological data collected during 2012 and 2013. These data were collected as part of a larger study of groundwater recharge estimation using the Water Table Fluctuation Method (Patros, unpublished data, 2015). These data included surface elevations and coordinates, saturated hydraulic conductivities ( $\mathrm{K}_{\text {sat }}$ ), and hydraulic heads, as well as weather and soil (texture, moisture contents, layer thicknesses) data.

The area was surveyed using a Total Station transit unit, which was used for elevation and area measurements. An arbitrary base was located and set to an elevation of $100 \mathrm{~m}$. Subsequent measurements were recorded as either above or below this base (Tamang et al., unpublished study, 2014). These data were then corrected for the proper elevation ( $\mathrm{m}$ ASL). Figure 2 shows a contour map of the site, generated using ArcGIS. Installed at the site were 13 fully screened wells and 3 piezometers. Wells were constructed of several lengths of $2.54 \mathrm{~cm}$ diameter (case radius, $\mathrm{r}=1.27 \mathrm{~cm}$ ) PVC pipe. Wells were installed approximately $1-2.5 \mathrm{~m}$ below the ground surface with a $2.54 \mathrm{~cm}$ well screen radius (R). Of the wells installed, 2 were constructed with a screen length (L) of $70 \mathrm{~cm}$, while the remaining 11 were constructed with a screen length of $150 \mathrm{~cm}$. Effective screen lengths (Le) of the shorter-screened wells ranged from $83-95 \mathrm{~cm}$, while the effective screen lengths of the longer-screened wells ranged from $150-230 \mathrm{~cm}$.

Wells (AW, or Arboretum well) AW1R, AW2R, AW3, AW4 and AW9 were installed with Solinst Level Loggers to automatically record the depth to water every 5 minutes. Data were then downloaded using Solinst software. In the other wells and the piezometers without loggers, the depth to water was determined manually with a Solinst Mini Water Level Meter. This device consists of a sensor attached to a long cable with length markings. Upon contact with water, the device displays visual and audial cues and depth to water is read from the cable and recorded. The depth to water in the fully screened wells was then calculated by subtracting the height of the well protruding above the soil surface from the recorded depth. These depths were then subtracted from the elevation of the well to determine the height of the water table at that location. Water table height data was missing for March and September of 2012, and for February, March and December of 2013.

Precipitation data for both 2012 and 2013 was obtained from the Guelph Turfgrass Institute. Total precipitation during 2012 was $760.60 \mathrm{~mm}$, and $886.19 \mathrm{~mm}$ during 2013 (Guelph Turfgrass Institute 2013). The data collectors noted that precipitation was measured with a tipping bucket rain gauge, so precipitation estimates during winter months may not be entirely accurate.

Soil samples were taken from two pits using aluminum soil rings (length $=2.5 \mathrm{~cm}$; diameter $=4.7 \mathrm{~cm}$ ) at $30 \mathrm{~cm}$ intervals from $60-150 \mathrm{~cm}$ below the soil surface in Pit 1 , and every $20 \mathrm{~cm}$ from $0-200 \mathrm{~cm}$ in Pit 2 (Tamang et al., unpublished study, 2014). Soil properties, such as texture and saturated hydraulic conductivity, were measured in a laboratory setting. Using a hydrometer, texture was analyzed in accordance with standard methods outlined by Carter and Gregorich (2008). This analysis was conducted by placing a $40 \mathrm{~g}$ sample of deflocculated soil into a hydrometer and measuring the density (g/litre) at 40 seconds $\left(\mathrm{R}_{40}\right)$, and at 7 hours $\left(\mathrm{R}_{7}\right)$. These were then used, along with a density 
reading of a calibration solution $\left(\mathrm{R}_{\mathrm{L}}\right)$, to determine the percentage of sand, clay, and silt in the soil, in equation [4]:

$$
\begin{gathered}
\text { Sand } \%=100-(R 40-R L) \times 100 / \text { oven } \\
\quad-\text { dried soil weight in } g \\
\text { Clay } \%=\left(\begin{array}{rl}
\text { R } 7-\text { RL }) \times 100 / \text { oven } \\
- \text { dried soil weight in } g
\end{array}\right. \\
\text { Silt } \%=100-(\text { sand } \%+\text { clay } \%)
\end{gathered}
$$

Hydraulic conductivities of the soil samples were determined using the falling head method. Soil cores were placed directly in a beaker and submerged with water until completely saturated. A standpipe was then placed above the unit and attached to the core. Water was poured into the tube until a certain height $\left(h_{o}\right)$ was reached, and then was allowed to drain through the soil for several seconds. During this time, the water fell to a second height $(h)$, and the time $(t)$ was recorded. The value of $\mathrm{K}_{\mathrm{sat}}$ was determined using equation [5] (Fetter 2001):

$$
K_{s a t}=\frac{d_{t}^{2} L}{d_{c}^{2} t} \ln \left(\frac{h_{o}}{h}\right)
$$

where $d_{t}$ is the inside diameter of the falling head tube, $d_{c}$ is the diameter of the sample chamber, $\mathrm{L}$ is the length of the sample [given in units of L], $t$ is the allotted time [t] and $h_{o}$ and $h$ are the initial and final values of head [L], respectively (Fetter 2001; Carter and Gregorich 2008).

\section{Site modelling and flow calculations}

The aforementioned data were used to create a 3-D conceptual model of the Arboretum site. For the purpose of this study, a trial version of Visual MODFLOW Flex v2014.2, a MODFLOW Graphical User Interface developed by Schlumberger Water Services, was used. This program accepts various forms of preprocessed geospatial and tabular data to create 3-D conceptual and numerical models of groundwater flow and transport. ArcMap v10.2 was used to produce shapefiles with georeferenced data to build an accurately scaled model. All data were projected in Transverse Mercator and the UTM NAD 1983 Zone 17N coordinate system. Tabular data were entered into ArcMap in order to display each $x, y$, and $z$ coordinate (in meters) as a point, polyline or polygon. The purpose of this was to create points that generated the surface and soil layers through interpolation, as well as the position, depths and effective screen lengths of each well. This was also used to specify the upper and lower boundaries and areal extent of the site. An areal extent of $1108 \mathrm{~m}^{2}$, which encompassed the maximum $x$ and $y$ range, was used to define the boundaries. A line along the north $x$ axis and the outline of the pond provided the constant head boundaries within the model.

The model required the creation of each geologically distinct layer. To do so, three soil layers were constructed by correlating textures between each well borehole and each pit. This process involved some assumptions about the soil distribution. During the excavation of the gravel pit, as noted above, the soil that makes up much of the site was moved by machinery. In creating the soil layers for the model, it was assumed that the layers were placed in a way that maintained the original soil structure. Three distinct soil layers were created: an upper layer of sandy loam from 0 to $60 \mathrm{~cm}$; a layer of loam from 60 to $160 \mathrm{~cm}$; and another layer of sandy loam from 160 to $200 \mathrm{~cm}$. The depth to each horizon was then subtracted from the well elevation to create point shapefiles for use in the conceptual modelling stage. Using the modelling software, interpolated 3-D surfaces and layers were then created.

Horizontal hydraulic conductivities were calculated by taking the arithmetic means of the $\mathrm{K}_{\mathrm{sat}}$ values (obtained through the falling head permeameter tests) in each layer in equation [6] (Fetter 2001):

$$
K_{x, y} a v g=\sum_{m=1}^{n} \frac{K_{h m} b_{m}}{b}
$$

where $b$ is the total formation (aquifer) thickness [L], $b_{m}$ is the thickness of layer $m[\mathrm{~L}]$ and $K_{h m}[\mathrm{~L}] /[\mathrm{t}]$ is the horizontal hydraulic conductivity of layer $m$.

The Dupuit equation [2] was used to calculate the flow of water over the site for each month. The northernmost well, AW4, was considered $h_{1}$, and the southernmost well, AW3, was considered $h_{2}$, separated by a distance of $22 \mathrm{~m}$. Elevations were all given in relation to sea level (m ASL), which created unrealistic discharges when entered into the Dupuit equation. To correct for this, the elevation of the bedrock (approximately $325 \mathrm{~m}$ ) was subtracted from the head data so that flow was only considered in the top 10-7 $\mathrm{m}$ of material. This value was then multiplied by the width of the study area $(25 \mathrm{~m})$ to arrive at a volumetric flux, $\mathrm{Q}\left[\mathrm{L}^{3} / \mathrm{t}\right]$. It was assumed that the water in AW3 approximated the pond elevation, and that the slope of the water table was equal to the hydraulic gradient.

Flow direction was determined by contouring the hydraulic heads within three wells. Wells chosen for this purpose were AW3, AW4, and AW5. The process involved plotting the three wells and their measured heads, and then calculating the hydraulic gradient between each pair of wells. The gradients were then contoured between each well with equipotential lines. Flow lines were then drawn perpendicular to these contour lines to determine the general direction of groundwater flow.

\section{Results}

\section{Conceptualmodelling}

The conceptual3D model of the site, including soil layers, can be seen in Figure 3, which has a vertical exaggeration of 3 to better illustrate the topography.

\section{Calculations of lateral ground water flow}

Figure 4 shows the hydraulic heads in wells AW3 (southernmost) and AW4 (northernmost) over the course of 2012 and 2013, and the statistical summary for each well. As noted above, total precipitation during 2012 was $760.60 \mathrm{~mm}$, 
and $886.19 \mathrm{~mm}$ during 2013 (Guelph Turfgrass Institute 2013). In 2012, water table height in both wells increased from January to June, at which point it declined steadily until July. During this period, from January to June of 2012, water levels in AW3 were higher than in AW4, indicating a flow towards AW4. In July 2012, the head in AW3 dropped below that of AW4, showing a distinct reversal in flow direction.

At some point during January-February 2013, the flow again changed direction, flowing from AW3 to AW4. Water table heights in both wells reached their peak during the spring of 2013, around the month of April. The difference between heads again decreased as November approached. Data are missing for December 2013, and accordingly, it is not clear whether the pattern again reversed around this time. Variance in hydraulic head in AW3 (standard deviation = $0.65 \mathrm{~m}$ ) was approximately 1.8 times greater than in AW4 (standard deviation $=0.36 \mathrm{~m}$ ). This is likely due to surface water's quicker response time than groundwater to rainfall. The pond surface (which AW3 was assumed to approximate) displays a higher variation than groundwater level within the soil, as it responded much more quickly to the added rain. Figure 5 shows the volumetric flow rate, $\mathrm{Q}$ ( $\mathrm{m}^{3} /$ day), using the Dupuit equation [2], with well AW4 as $h_{1}$ and well AW3 as $h_{2}$. Figure 5 also shows the statistical summary for each flow pattern. Groundwater flow is therefore considered in relation to the north-south axis, with well (AW4) to the north, and the pond (well AW3) to the south. Northward flow, the flow that was typical during early 2012, is indicated by a negative flow direction, while southward flow, the reversed flow, is indicated by a positive flow direction.

In the period from July 2012 to April 2013, when flow was in the direction of AW3, the discharge rate was notably higher (reaching up to $24.62 \mathrm{~m}^{3} /$ day). During the peak of the second reversal, toward AW4, the discharge maximum was close to the previous period (maximum $-20.81 \mathrm{~m}^{3} /$ day). For volumetric flow, standard deviation is approximately $1.5 \mathrm{x}$ greater during southward flow ( $\mathrm{sd}=9.96 \mathrm{~m}^{3 /}$ day) than in northward flow (sd $=6.43 \mathrm{~m}^{3} /$ day). The volumetric flow rate, Q ( $\mathrm{m}^{3} /$ day), was nearly twice as great during spring 2013 (peaking at $-20.81 \mathrm{~m}^{3} /$ day) than during spring in 2012 (peaking at $-10.80 \mathrm{~m}^{3} / \mathrm{day}$ ). Figure 6 and Figure 7 show the conceptually modelled water table during regular flow (prior to reversal) and during reversed flow, respectively.

\section{Discussion}

The local groundwater flow system in the Arboretum site underwent distinct reversals in lateral flow direction and volumetric flow rates throughout the years 2012 and 2013. This suggests that the Arboretum system is a local-scale regime subject to changes in groundwater flow direction in response to climatic variability. This type of system has the potential to be further analyzed using groundwater modelling programs, including the more sophisticated numerical capabilities of MODFLOW. Given the nature of this study, a full-scale numerical analysis could not be conducted, but the analytical solutions applied revealed what may be the overall patterns occurring at the study site.

The first flow reversal in 2012 followed an increase in water table height, likely corresponding to the spring melt from March through to June. During this time, groundwater flowed south from well AW4 towards AW3. This suggests that the pond acts as a local recharge zone for the aquifer. The flow continued in this direction until July, after which point a significant drop in pond level can be seen (Figure 4). Leading up to this point were relatively low precipitation rates, which likely created dry conditions and thus a higher evaporative demand on the pond than on the soil. Evaporation was greatest during the summer in 2012, likely due to higher temperatures and drier conditions. The pond responded to higher evaporative demand with a lowered water level, while the water in the soil responded more slowly. This gradually shifted the gradient, with the higher hydraulic head now north of the pond. Flow shifted towards the south, discharging in the pond and remaining fairly constant during the winter, prior to the spring melt in 2013. Around this time, the flow direction again became northward, with the pond once again acting as a local recharge zone. This situation is very similar to the one discussed by Fraser et al. (2001), who observed that changes in precipitation patterns resulted in a shift of the hydraulic gradient. Although their study was focused on small peatlands, the hydrologic environments were similar to those discussed in this study in that they remain driven primarily by local-scale flow regimes. Therefore, short-term changes in weather are more likely to drive a differential response in head between subsurface and surface waters. It is unknown whether these effects are observable in larger-scale flow systems, as the effects here are likely due to short, quick changes to inflows and outflows.

As 2012 was a drier year than 2013, the volumetric flow rates during the first northward flow phase were lower than during the second. In a separate study of this site, Tamang et al. (unpublished study, 2015) demonstrated that there was an average of $25 \mathrm{~mm}$ more monthly deep drainage in 2013 than in 2012. Greater deep drainage may entail greater groundwater recharge, which could explain the comparatively increased discharge rate during the spring of 2013 (Figure 5).

The water table elevations remained fairly constant over the winter months, despite a gradient showing that water continued to flow laterally. It is possible that this system is continually fed by a larger, intermediate-scale regime, or by more complex local systems outside the scope of this study. The larger intermediate flow system, as well as other local systems, may maintain flow into and out of the pond, but their involvement is only speculative at this time.

\section{Conclusion}

This study analyzed the lateral groundwater flow in a shallow, unconfined, unconsolidated aquifer over the course of a comparatively dry year, 2012, and a comparatively wet 
year, 2013. A conceptual 3-D model was created using Visual MODFLOW Flex and ArcGIS, and flow was calculated using the Dupuit equation. Conceptual modelling demonstrated that a small system such as this one has potential for further modelling, but adequate collection of data concerning topography, geologic layers, and bedrock depth must be carried out in order to obtain significant results.

The investigation of flow patterns revealed that for a period of approximately 10 months, from July, 2012, to May, 2013, the lateral groundwater flow direction reversed, before returning to its previous state in the late spring of 2013.

A number of assumptions and sources of error were apparent in this study. For soil layer creation, we assumed that there were three unique layers that could be modelled. We assumed that the aquifer layers were isotropic and homogenous, and we gave these layers laboratory-derived $\mathrm{K}_{\text {sat }}$ values, as opposed to an in situ $\mathrm{K}_{\text {sat }}$ values. Additionally, we assumed that the layers had continuous thickness throughout the modelled area.

For flow calculations using the Dupuit equation, we assumed that the aquifer material was homogenous, is otropic, and that the water table approximated the hydraulic gradient. The hydraulic heads of the northernmost and southernmost wells (AW4 and AW3, respectively) were used as the parameters $h_{1}$ and $h_{2}$, and it was assumed that the water levels in AW3 approximated the pond surface. Any differences in the water table between these wells (water table mound, for example) were not considered. Where soil or hydraulic head data were missing, they were estimated using linear interpolation from nearby wells.

Regarding future climatic change, this relatively smallscale study suggests that differences in rainfall from year to year may impact groundwater flow patterns. The flow direction reversal and the decreased flow volume observed in this study were likely due to the comparative lack of rain in 2012. With the increasing frequency of floods and droughts, as predicted by climate models, there is the possibility that flow reversals will occur in waters which do not typically undergo them. This might cause changes in shallow aquifers used by communities as sources of drinking water. In addition, flow reversals may cause accumulations of nutrients, salts, or bacteria in a surface water body to contaminate local aquifers.

\section{Recommendations}

Beyond the bounds of this study, the nature of the flow patterns occurring at the Arboretum site remains unclear. As flow was only considered for a relatively small area, the local and intermediate patterns that characterize the remaining pond outskirts could not be determined. Further research and modelling could investigate these others patterns, and can examine the effects generated by the larger-scale flow system that encompasses the local regime in this study. Measuring the hydraulic properties and actual seepage into or out of the pond may also improve results and allow for better numerical modelling. A longer-term study of water table fluctuations might confirm whether these reversals are part of an annual pattern, or were due to the anomalously dry year. The small and inconsistent sample size for each month often meant that only one water table height was used for an entire month. A more accurate understanding of the flow regime at this site could be ascertained with more frequent well measurement. Calculations of flow using in situ methods for determining $\mathrm{K}_{\text {sat}}$, such as the slug test, might be more appropriate for future studies of this type than using laboratory-derived $\mathrm{K}_{\text {sat }}$ values. Furthermore, future research is encouraged to examine changes in water quality caused by alterations to groundwater flow patterns.

\section{Acknowledgements}

The first author would like to thank Gary Parkin and Thair Patros for providing the data, guidance, indispensable feedback, and patience necessary to undertake this project.

\section{References}

Arboretum Master Plan Steering Committee. 2004. Arboretum master plan. Guelph (ON): University of Guelph. 80 p.

Bajc AF, Russell HA, Sharpe DR. 2014. A three-dimensional hydrostratigraphic model of the Waterloo Moraine area, southern Ontario, Canada. Canadian Water Resources Journal/Revue canadienne des ressources hydriques 39(2): 95-119.

Best A. (2013). Non-point source pollution in quaternary glacial deposits, Guelph, Ontario [master's thesis]. Guelph (ON): University of Guelph. 129 p.

Brunner P, Simmons CT, Cook PG, Therrien R. 2010. Modeling surface water-groundwater interaction with MODFLOW: some considerations. Groundwater. 48(2): 174-180.

Carls on CS, Lyford FP. 2005. Simulated ground-water flow for a pond-dominated aquifer systemnear Great Sandy Bottom Pond, Pembroke, Massachusetts. US Geological Survey scientific investigations report 2004-5269. Reston(VA): US Geological Survey. 43 p.

Carter MR, Gregorich EG. 2008. Soil sampling and methods of analysis. $2^{\text {nd }}$ ed. Boca Raton (FL): Taylor and Francis Group. 198 p.

Guelph Turfgrass Institute. 2013. Hourly climate data and weather records [Internet]. Guelph (ON): University of Guelph. Available from https://www.uoguelph.ca/ses/service/weather-records

National Research Council (NRC) (US). 1990. Ground water models: scientific and regulatory applications. Washington (DC): The National Academies Press. 303 p. 
Fetter CW. 2001. Applied hydrogeology. $4^{\text {th }}$ ed. Upper Saddle River. (NJ): Prentice Hall. 588 p.

Fraser CJD, Roulet NT, Lafleur M. 2001. Groundwater flow patterns in a large peatland. Journal of Hydrology. 246(1): 142-154.

Gartner Lee Limited. 2004. Guelph/Eramosa Township regional groundwater characterization and wellhead protection study. Markham (ON): Gartner Lee Limited. $96 \mathrm{p}$.

Gregor M. 2012. Surface-and groundwater quality changes in periods of water scarcity. New York (NY): Springer.

$230 \mathrm{p}$.

Karrow PF. 1968. Pleistocene geology of the Guelph area, southern Ontario. Ontario Department of Mines geological report 61. Toronto (ON): Ontario Department of Mines. 38 p.

Rajamanickam R, Nagan S. 2010. Groundwater quality modeling of Amaravathi river basin of Karur district, Tamil nadu, using visual Modflow. International Journal of Environmental Sciences. 1(1): 91-108.

Rodhe A, Seibert J. 2011. Groundwater dynamics in a till hillslope: flow directions, gradients and delay. Hydrological Processes. 25(12): 1899-1909.

Sophocleous M. 2002. Interactions between groundwater and surface water: the state of the science. Hydrogeology Journal. 10(1): 52-67.

Taylor RG, Scanlon B, Döll P, Rodell M, Van Beek R, Wada Y, Longuevergne L, Leblanc M, Famiglietti JS, Edmunds M, et al. 2012. Ground water and climate change. Nature Climate Change 3(4): 322-329.

Touhami I, Andreu JM, Chirino E, Sánchez J.R, Moutahir H, Pulido-Bosch A, Martínez-Santos P, Bellot J. 2013. Recharge estimation of a small karstic aquifer in a semiarid Mediterranean region (southeastern Spain) using a hydrological model. Hydrological Processes 27(2): 165-174.

Wang S, Shao J, Song X, Zhang Y, Huo Z, Zhou X. 2008. Application of MODFLOW and geographic information systemto groundwater flow simulation in North China Plain, China. Environmental Geology. 55(7). 1449-1462.

Winter TC, Harvey JW, Franke OL, Alley WM. 1998. Ground water and surface water: a single resource. US Geological Survey circular 1139. Denver (CO): US Geological Survey. 87 p.

Zomorodi K. 1991. Evaluation of the response of a water table to a variable recharge rate. Hydrological Sciences Journal. 36(1): 67-78. 


\section{Tables and Figures:}

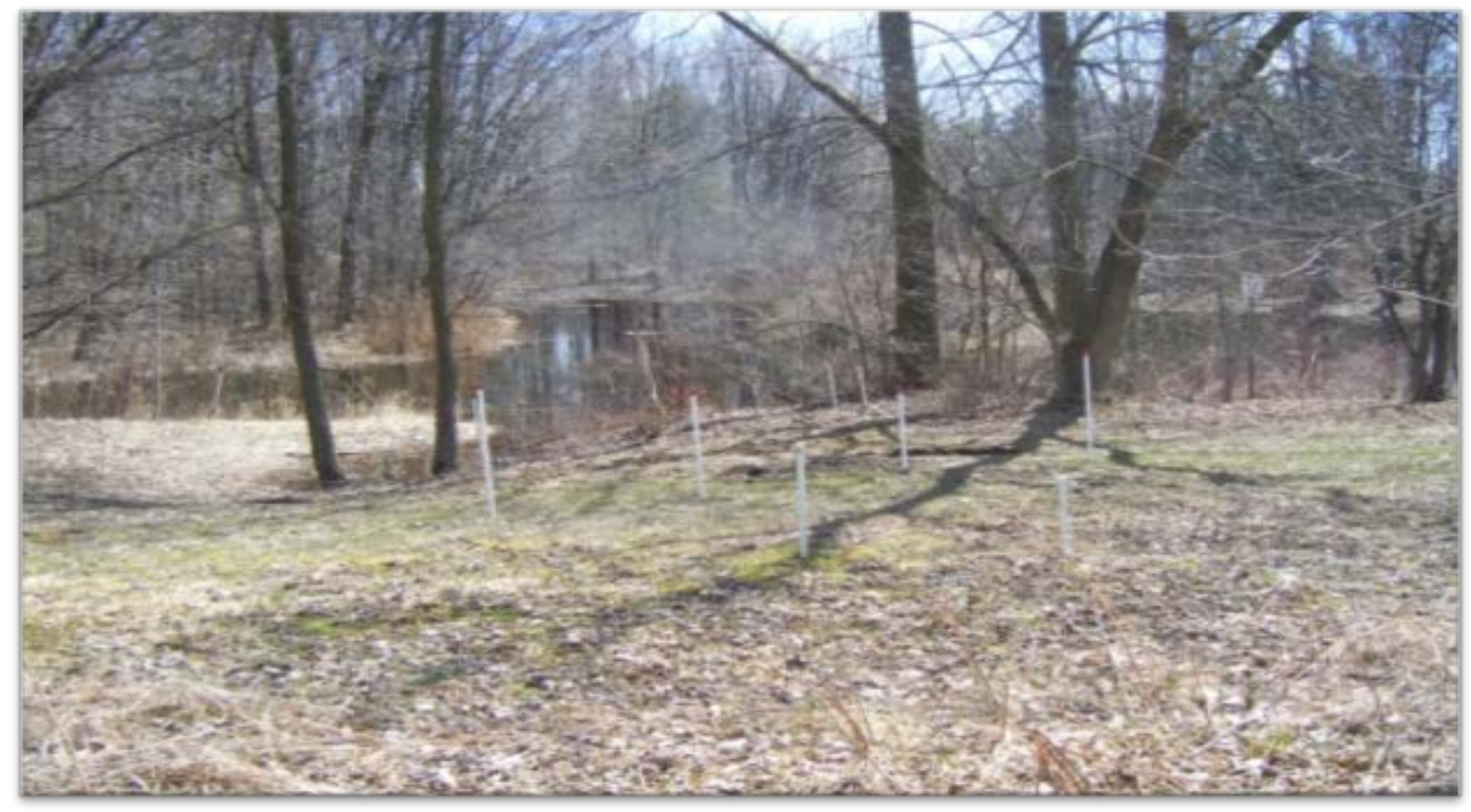

Figure 1: Arboretum study site (looking sourthward toward the pond), displaying fully screened wells, piezometers, and pond location (after Patros, unpublished study, 2015).

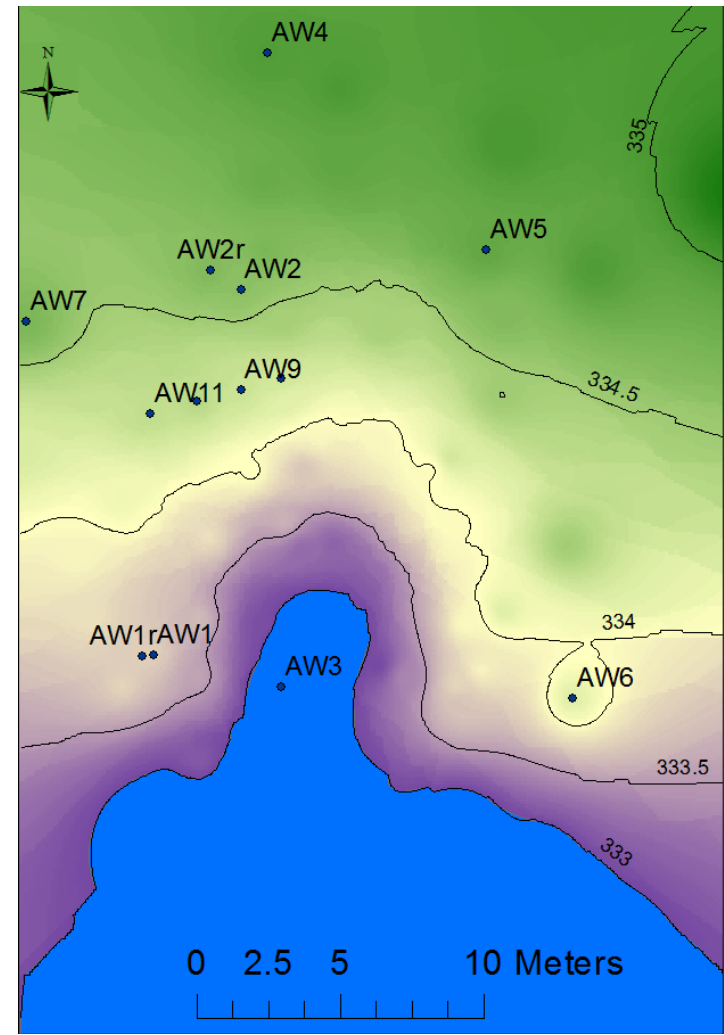

Figure 2: Surveyed study site contour map (contours of $0.5 \mathrm{~m}$ ) with well positions labeled (blue dots) and the location of the pond at an elevation of $333 \mathrm{~m}$ ASL. Map created within ArcMap. Note the relative positions of wells AW4 and AW3. 


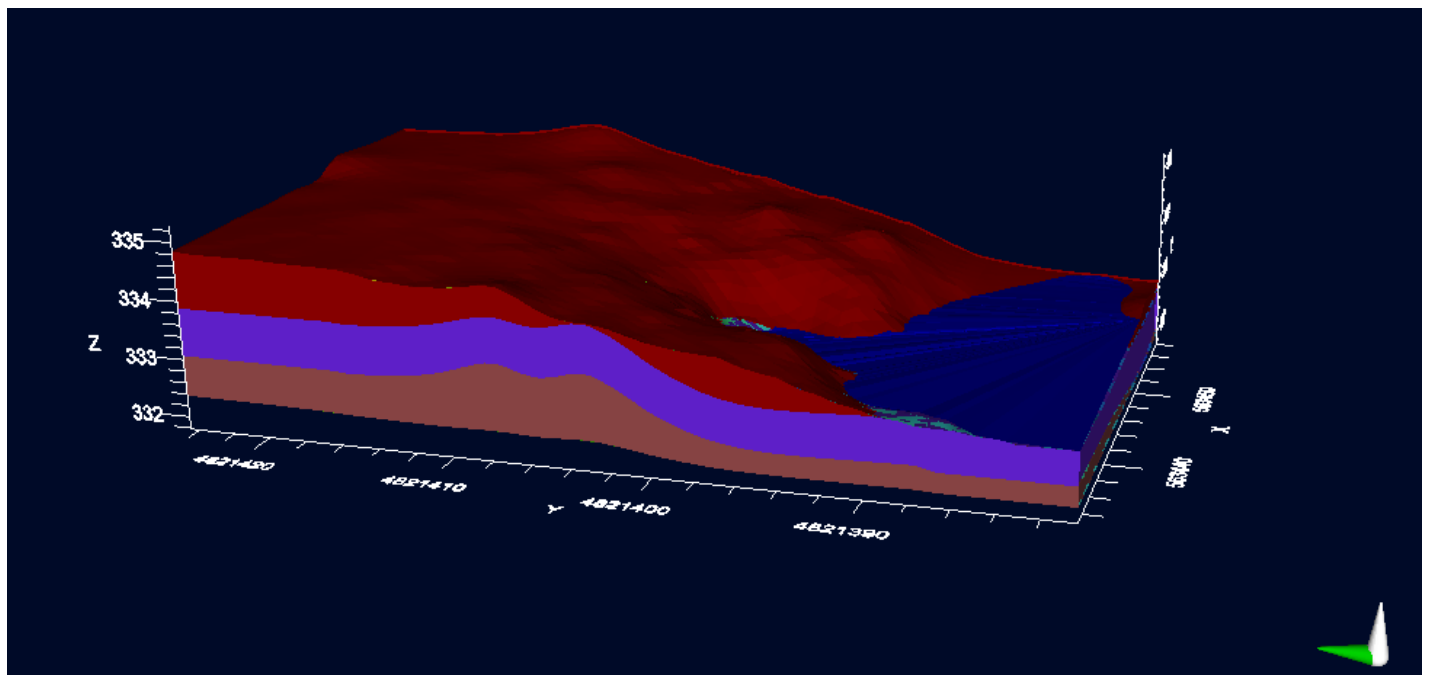

Figure 3: Conceptual geological model of the Arboretum site, featuring the pond (blue polygon) and constructed soil layers (red, an upper layer of sandy loam from 0 to $60 \mathrm{~cm}$; purple, a layer of loam from 60 to $160 \mathrm{~cm}$; and brown, a layer of sandy loam from 160 to 200 $\mathrm{cm})$. The vertical axis has an vertical exaggeration of 3 to better illustrate the topography. Well positions are not displayed in this image. The green arrow points north.

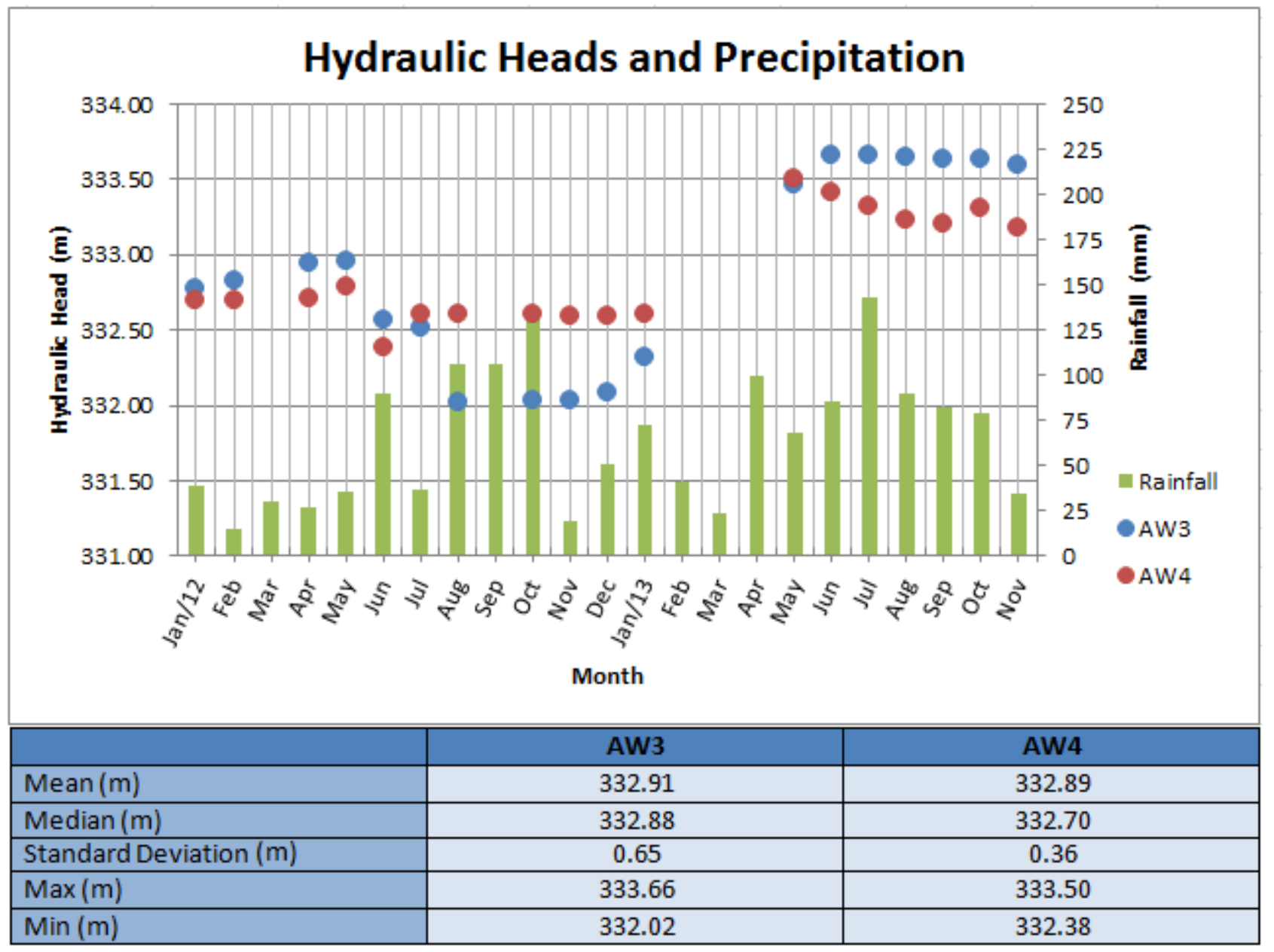

Figure 4: Graph of hydraulic heads and precipitation (top) in $\mathrm{m} \mathrm{ASL}$, and associated statistics (bottom) for wells AW3 and AW4.

Groundwater flow reversal can be seen where heads approach the same values, beginning in July 2012, and ending around May 
2013. Bottom of figure shows a comparison of the statistical summary of hydraulic heads, with overall greater heads and greater standard deviation in AW3 compared to AW4.

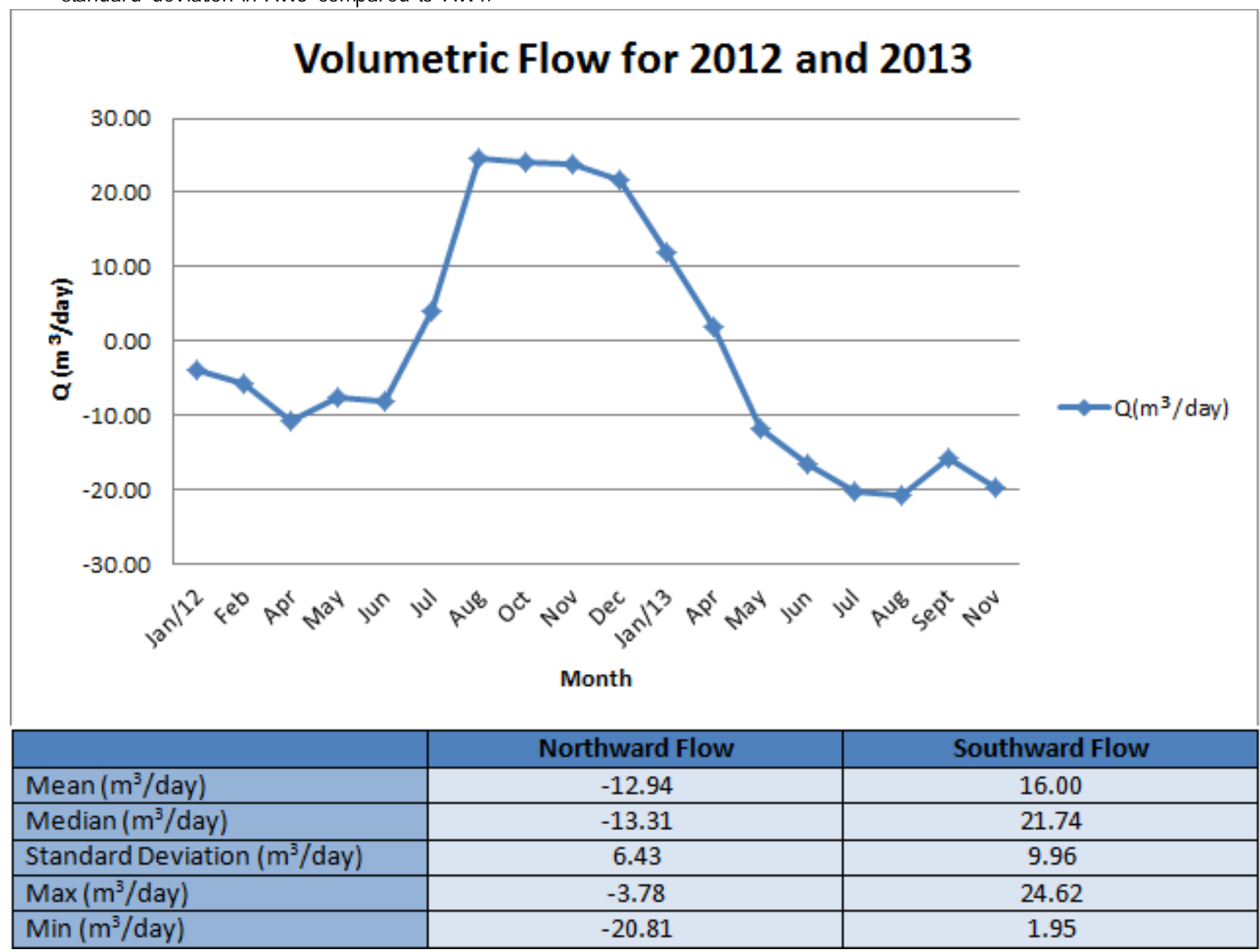

Figure 5: Graph of volumetric groundwater flow rates (m3/day) (top) over 2012 and 2013, and associated statistics (bottom). Negative values indicate negative hydraulic gradient and therefore negative flow direction (northward) and positive values indicate a positive gradient and positive flow direction (southward). Flow reversal can again be seen where the flow approaches $0.00 \mathrm{~m} 3 / \mathrm{day}$, and shift from negative to positive (July 2012), then from positive to negative (April - May 2013). Summary statistics display overall greater volumetric flow, and greater standard deviation, during southward than northward flow. 


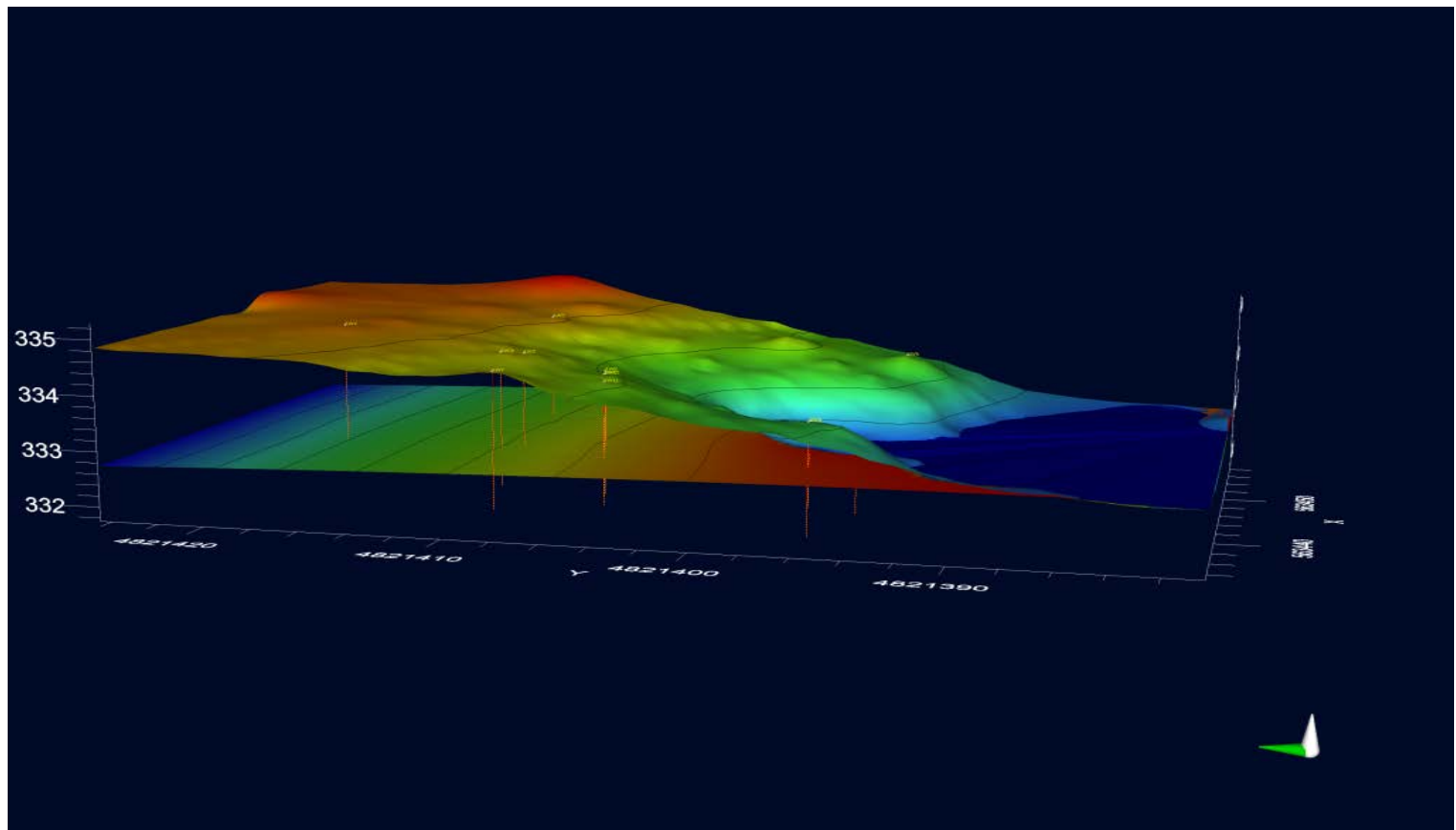

Figure 6: Visual MODFLOW conceptual model of groundwater flowing away from the pond, corresponding to northward flow phases (JanJuly 2012 and May-Nov 2013). Colour ramp displays red for areas of higher elevation (surface topography) or hydraulic head (water table), and blue for areas of low. Wells are displayed as red and yellow cylinders extending below the surface. The vertical axis has a vertical exaggeration of 3 to better illustrate the topography. The green arrow points north.

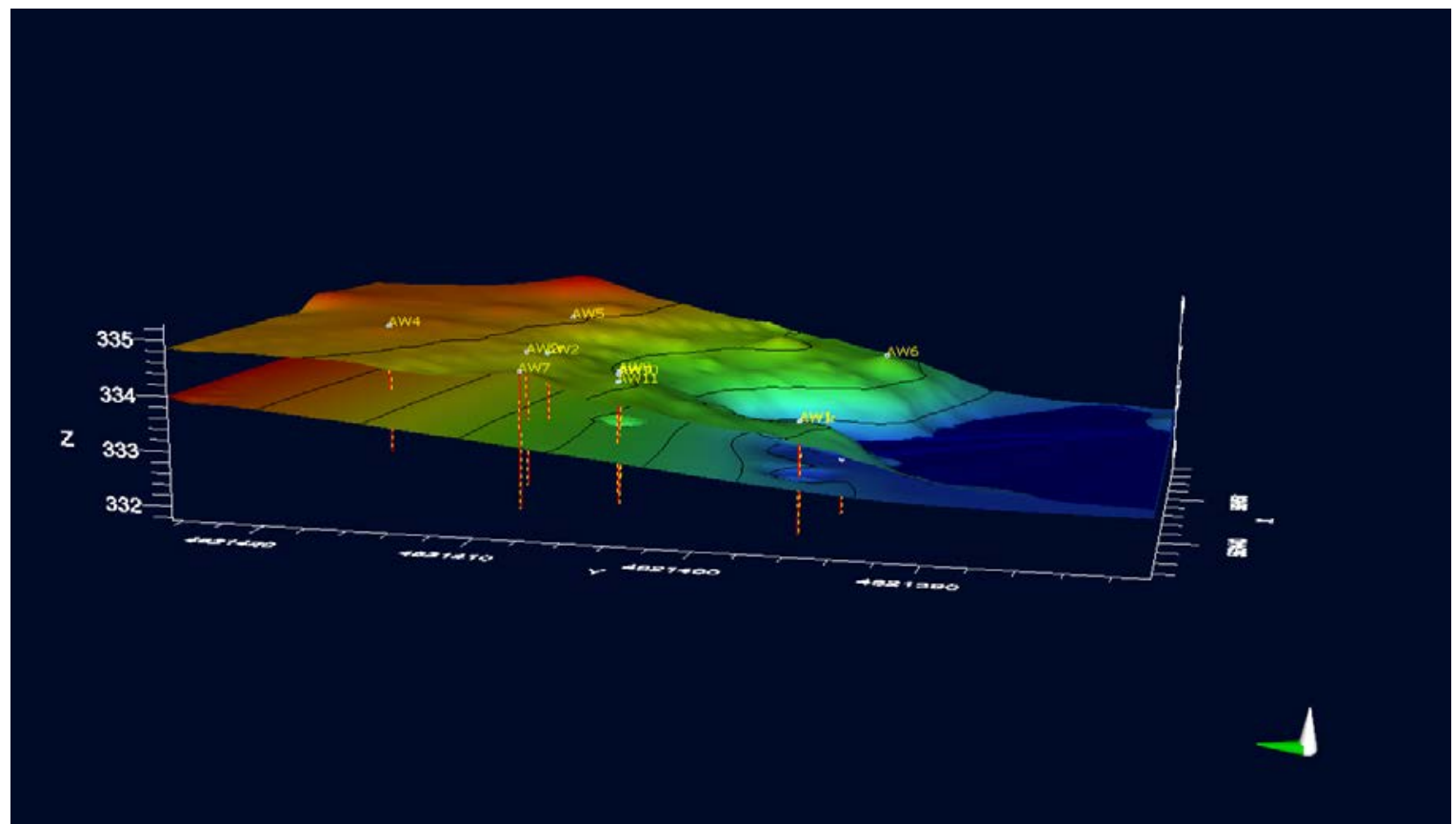

Figure 7: Visual MODFLOW conceptual model of water table flowing towards the pond during southwards flow phase (July 2012-May 2013). Colour ramp displays red for areas of higher elevation (surface topography) or hydraulic head (water table), and blue for areas of low. Wells are displayed as red and yellow cylinders extending below the surface. The vertical axis has an exaggeration of 3 to better illustrate the topography. The green arrow points north. 


\section{Supplementary Information:}

Supplementary Table 1: Description of the wells and piezometers installed at the Arboretum study site (after Patros, unpublished data, 2010).

\begin{tabular}{|c|c|c|c|c|c|c|c|c|c|}
\hline \multirow[b]{2}{*}{ Group } & \multirow{2}{*}{$\begin{array}{l}\text { Well/Pei- } \\
\text { zometer }\end{array}$} & \multicolumn{5}{|c|}{ Description } & \multirow{2}{*}{$\begin{array}{c}\text { Elevation } \\
\text { (m ASL) }\end{array}$} & \multirow{2}{*}{$\begin{array}{l}\text { DBMP } \\
\text { (m) }\end{array}$} & \multirow{2}{*}{$\begin{array}{l}\text { Installation } \\
\text { method }\end{array}$} \\
\hline & & SL (m) & Le (m) & B (m) & $\mathrm{S}(\mathrm{m})$ & DBS S (m) & & & \\
\hline \multirow{2}{*}{ I } & 1 & 0.70 & 0.95 & 0.30 & 0.30 & 1.55 & 333.773 & 2.3 & $\begin{array}{l}\text { Polaris/hand- } \\
\text { augered }\end{array}$ \\
\hline & 1R & $* 1.50$ & 1.89 & 0.15 & - & 2.04 & 333.781 & 2.75 & Polaris \\
\hline \multirow{2}{*}{ II } & 2 & *1.50 & 1.57 & 0.15 & 0.10 & 1.82 & 334.606 & 2.57 & Hand-augered \\
\hline & $2 \mathbf{R}$ & $* 1.50$ & 2.32 & 0.15 & - & 2.47 & 334.666 & 3.01 & Polaris \\
\hline III & 3 & 0.70 & 0.83 & 0.20 & - & 1.03 & 332.794 & 2.22 & Polaris \\
\hline IV & 4 & $* 1.50$ & 1.565 & 0.85 & - & 2.42 & 334.954 & 3.265 & Polaris \\
\hline V & 5 & $* 1.50$ & 1.59 & 0.81 & - & 2.40 & 334.845 & 3 & Polaris \\
\hline VI & 6 & $* 1.50$ & 1.60 & 0.47 & - & 2.07 & 334.165 & 3.47 & Polaris \\
\hline VII & 7 & $* 1.50$ & 1.90 & 0.50 & - & 2.40 & 334.699 & 3.52 & Polaris \\
\hline VIII & 8 & $* 1.50$ & 1.51 & 0.55 & - & 2.06 & 334.251 & 3.52 & Polaris \\
\hline IX & 9 & $* 1.50$ & 1.63 & 0.60 & - & 2.23 & 334.277 & 3.63 & Polaris \\
\hline $\mathbf{X}$ & 10 & $* 1.50$ & 1.60 & 0.80 & - & 2.40 & 334.365 & 3.52 & Polaris \\
\hline XI & 11 & $* 1.50$ & 1.48 & 0.60 & - & 2.08 & 334.328 & 3.52 & Polaris \\
\hline
\end{tabular}

Abbreviations:

$\begin{array}{ll}\text { AW } & \text { Arboretum well } \\ \text { R } & \text { Replicate } \\ \text { SL } & \text { Screen length } \\ \text { Le } & \text { Effective screen length } \\ \text { S } & \text { Soil } \\ \text { DBSS } & \text { Depth below soil surface } \\ \text { m } & \text { Meters } \\ \text { m ASL } & \text { Meters above sea level } \\ \text { DBMP } & \text { Depth below mounted point }\end{array}$

